\title{
The utilization of intravenously administered carotene and vitamin $A$ emulsion by rats and goats
}

\author{
By W. A. McGIlllivRAY, S. Y. THOMPSON* AND N. A. WORKER \\ Biochemistry Department, Massey Agricultural College (University of New Zealand), \\ Palmerston North, New Zealand \\ (Received 24 August 1956-Revised 20 October 1956)
}

The utilization of intravenously administered aqueous dispersions of carotene has been investigated by a number of workers (e.g. Church, MacVicar, Bieri, Baker \& Pope, I954; Bieri \& Pollard, I954; Bieri, 1955; Kon, McGillivray \& Thompson, I955; McGillivray, Thompson \& Worker, 1956), and it is now clearly established that carotene so administered can be converted into vitamin $A$ in rats, rabbits, sheep and chicks. Further, to help interpret their findings with carotene dispersions, Kon et al. (1955) investigated the effect of injecting intravenously aqueous dispersions of vitamin A alcohol and ester and found that, despite rapid and considerable destruction of the vitamin $A$, a proportion of the dose was taken up by the liver and retained in an apparently normal manner. Owing, however, to the nature of the surface-active agent employed (Tween 40, polyoxyethylenesorbitan monopalmitate) these dispersions are highly unphysiological, and it seemed of interest to investigate the utilization of carotene and vitamin A emulsions prepared without the use of surface-active agents of this type and with the particle size of the dispersed fat phase of the same order as that of the blood chylomicrons.

\section{EXPERIMENTAL}

\section{Preparation of carotene and vitamin $A$ emulsions}

The method used for the preparation of the emulsions for intravenous administration was essentially that described by Shafiroff, Mulholland, Roth \& Baron (I949). Glucose $(5 \circ \mathrm{g})$ and gelatin $(20 \mathrm{~g})$ dissolved separately in water were blended in a Waring Blendor with $100 \mathrm{~g}$ arachis oil containing the appropriate quantities of either carotene or vitamin A alcohol or palmitate. The volume was adjusted to I 1 . with water and the suspension homogenized at $3500 \mathrm{lb}$./sq.in. in a single-stage, piston-type homogenizer to give an emulsion of average particle size about $0.6 \mu$ and few particles larger than I $\mu$ diameter.

As the carotene and vitamin A were destroyed fairly rapidly even when emulsions were stored under nitrogen at low temperatures, all emulsions were used as soon as possible after preparation.

Carotene (about $88 \% \beta$-carotene), vitamin $\mathrm{A}$ alcohol and palmitate and $\alpha$-tocopheryl acetate were all obtained from L. Light and Co. Ltd.

\footnotetext{
* On leave from the National Institute for Research in Dairying, Shinfield, near Reading, England.
} 


\section{Animals}

All rats were of the Wistar strain rendered partially deficient in vitamin $A$ as described previously (McGillivray et al. 1956). Adult animals 200-500 g in weight were used, and all injections were into the jugular vein exposed by ventral neck incision.

The goats were predominantly Saanen, in full lactation, with normal vitamin A reserves. They were tethered on pasture throughout the experimental period. All injections were into, and blood samples were drawn from, the jugular vein.

\section{Estimation of vitamin $A$ and carotene}

All estimations were carried out as described by Thompson, Ganguly \& Kon (r949) with the slight modification since described (Kon et al. 1955).

RESULTS

\section{Intravenous administration of carotene and vitamin $A$ emulsions} to rats partially deficient in vitamin $A$

Blood plasma and liver levels attained at intervals after the intravenous administration of carotene or vitamin A alcohol or palmitate emulsions to rats are shown in Table $\mathbf{I}$. It is apparent that vitamin A palmitate administered in this way is well utilized, as indicated by liver storage, over half of the dose being accounted for in the plasma and liver at all time intervals studied. The increased vitamin $\mathrm{A}$ alcohol level in both plasma and liver at the shorter time intervals indicates some hydrolysis of the palmitate, but at $4 \mathrm{~h}$ most of the vitamin in the liver was in the esterified form and at $24 \mathrm{~h}$ re-esterification was complete.

Even taking into consideration that the dose of vitamin A alcohol was only one-fifth of the dose of vitamin $A$ palmitate and that the rats given the vitamin $A$ alcohol were more depleted, it would appear, on the basis of the liver vitamin $A$ levels recorded in Exp. 2 (Table I), that vitamin A alcohol was not as well utilized as the palmitate.* If anything, these figures are probably higher than they should be, as the antimonytrichloride blue colour was somewhat atypical in all these measurements owing to the presence of artifacts.

In Exps. 3 and 4 (Table I) there was some indication of conversion of the emulsified carotene into vitamin A. At the shorter time intervals there was an increased plasma vitamin $A$ alcohol level succeeded by an increase in liver vitamin $A$ alcohol and finally esterification of this liver vitamin A. With $400 \mu \mathrm{g}$ carotene injected, the level of carotene in the liver showed no significant change from $5 \mathrm{~min}$ to $24 \mathrm{~h}$, although the level in the plasma fell from about $1000 \mu \mathrm{g} / \mathrm{r} 00 \mathrm{ml}$. to just a trace.

A feature of this work was the rapidity with which the carotene and vitamin A remaining in the plasma were destroyed after the blood was withdrawn from the animal. All assays were therefore carried out as soon as possible after the slaughter of the animals. This destruction was particularly marked with plasma carotene after injection of carotene emulsion; despite the precautions taken extremely variable plasma carotene levels were recorded. The plasma carotene levels are shown in Table I, therefore, as approximate means only. 


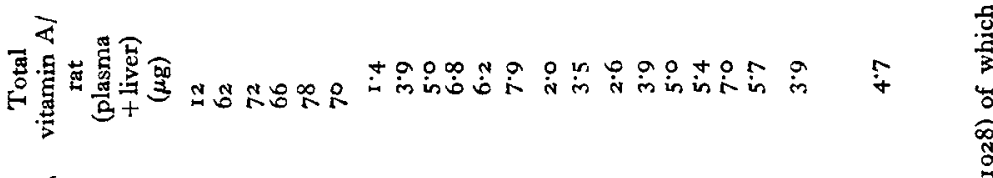

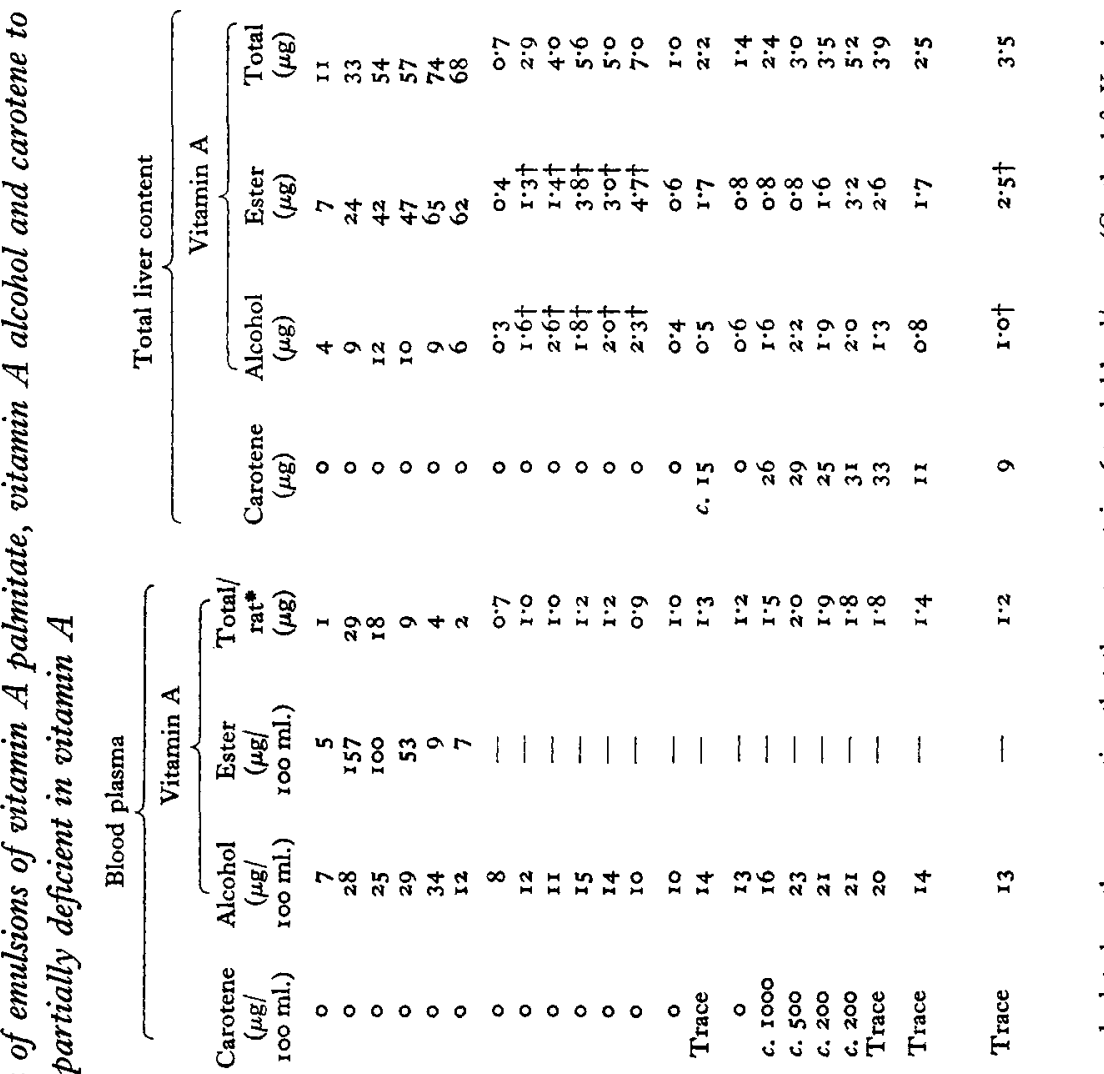

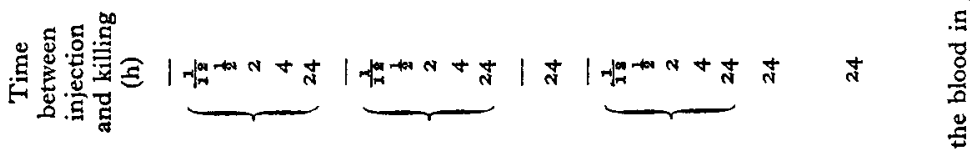

క

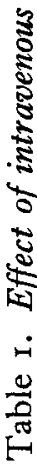

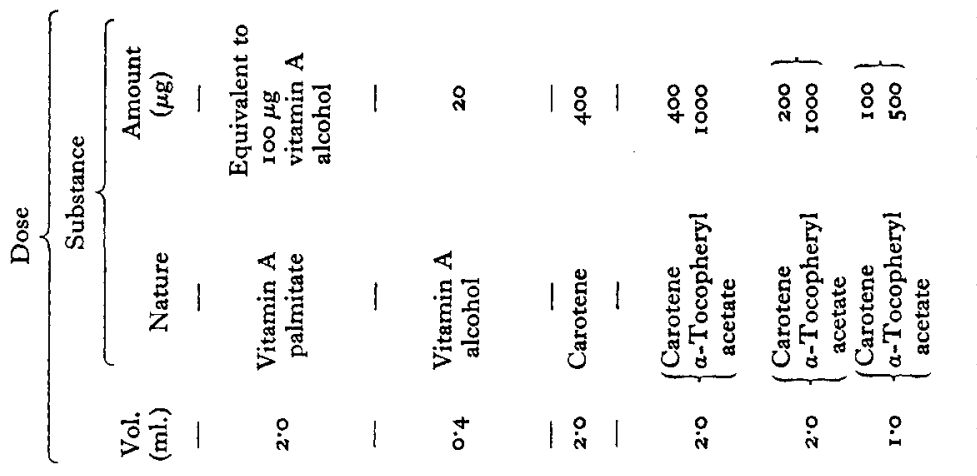

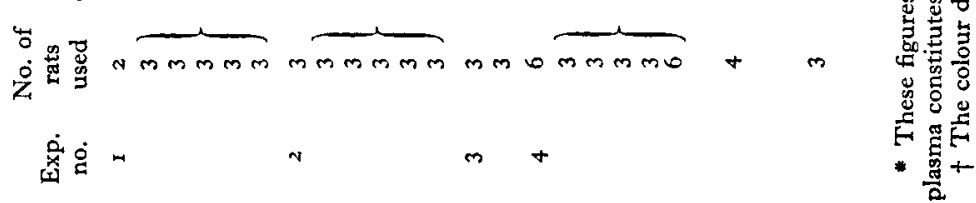




\section{Intravenous administration of carotene emulsions to lactating goats}

Carotene emulsions (10 $20 \mathrm{ml}$.) were injected intravenously into three lactating goats. In none was carotene detected in the milk drawn $2-48 \mathrm{~h}$ after injection, nor was there any significant increase in the vitamin $A$ ester or alcohol in the milk or blood plasma. Typical figures are given in Table 2 for one goat injected with the same carotene emulsion as was used for the rats recorded in Table I (Exp. 4).

Some goats and rats showed signs of distress after injection of the emulsion, and some of them died $4^{-24} \mathrm{~h}$ after injection.

Table 2. Levels of vitamin $A$ and carotene in blood plasma and milk fat after intravenous administration to a goat of $20 \mathrm{ml}$. emulsion containing $4 \mathrm{mg}$ carotene

\begin{tabular}{|c|c|c|c|c|}
\hline \multirow{2}{*}{$\begin{array}{l}\text { Time after } \\
\text { injection } \\
\text { (h) }\end{array}$} & \multicolumn{2}{|c|}{ Blood plasma* $(\mu \mathrm{g} / 100 \mathrm{ml})}$. & \multicolumn{2}{|c|}{ Milk fat* $(\mu \mathrm{g} / \mathrm{g})$} \\
\hline & $\begin{array}{l}\text { Vitamin A } \\
\text { alcohol }\end{array}$ & Carotene & $\begin{array}{c}\text { Vitamin A } \\
\text { ester }\end{array}$ & Carotene \\
\hline Before dosing & 30 & $\circ$ & 13 & $\circ$ \\
\hline$\frac{1}{12}$ & 32 & 13 & - & $\cdots$ \\
\hline$\frac{1}{2}$ & 28 & 6 & - & - \\
\hline I & 27 & 4 & - & - \\
\hline 2 & 28 & 4 & 12 & 0 \\
\hline 4 & 30 & 3 & I I & $\circ$ \\
\hline
\end{tabular}

* There was no measurable quantity of vitamin A ester in the blood plasma or of vitamin A alcohol in the milk fat.

\section{DISCUSSION}

Our finding that intravenously administered carotene emulsion is converted into vitamin A confirms that of Greenberg, Levenson \& Rose (1955), who demonstrated the appearance of vitamin $A$ in the rat after intravenous injections of a carotene emulsion specially prepared from carrot oil. (This emulsion was prepared by Endo Products Inc., New York, and contained $10 \%$ carrot oil and $7 \cdot 2 \%$ gelatin (R. Greenberg, private communication).) Conversion is much less efficient than that of aqueous carotene dispersions reported, for example, by Kon et al. (r955) with the same quantity of carotene; from the plasma vitamin A alcohol levels and the liver vitamin A alcohol and ester levels at the various time intervals, however, it would appear to follow a similar course, the vitamin A appearing first in the blood plasma as the alcohol, which is taken up by the liver and subsequently esterified.

With the vitamin $A$ alcohol emulsion, the net amount of vitamin $A$ that could be accounted for by the content in plasma and liver increased steadily from $2.5 \mu \mathrm{g}(13 \%)$ at $5 \mathrm{~min}$ to $6.5 \mu \mathrm{g}(33 \%)$ at $24 \mathrm{~h}$. This increase with time, in plasma and liver vitamin A together, was on a percentage basis much less with the palmitate emulsions, and it appears that considerably more of the dose of vitamin $A$ alcohol than of palmitate was taken up by other tissues, from which it was subsequently released and stored in the liver.

The utilization of vitamin A palmitate from an emulsion is of particular interest, since the vitamin A absorbed after oral administration is transported from the intestine to the storage organs in an esterified form (Thompson et al. 1949). If the utilization of this palmitate emulsion does to any extent simulate the uptake from the plasma of 
vitamin $\mathrm{A}$ ester in transport, it would appear to be a rapid and relatively efficient process, one-fifth of the dose being taken up in the first $5 \mathrm{~min}$ and almost half the dose in $\frac{1}{2} h$.

In the goat, although the mammary gland is capable of utilizing dietary fats by a direct uptake of blood chylomicrons (cf. review by Glascock, 1954), it would appear that the membrane is either impermeable to fat globules of the type or size present in the carotene emulsion or that the carotene is destroyed or removed from the fat during the process.

\section{SUMMARY}

I. The utilization by rats and by lactating goats of intravenously administered emulsions of carotene and of vitamin A alcohol and palmitate has been investigated.

2. In the rat vitamin A palmitate was rapidly and relatively efficiently taken up by the liver, almost half the dose appearing in the liver in $\frac{1}{2}-2 \mathrm{~h}$.

3. Less than one-third of the dose of vitamin A alcohol injected into rats was stored in the liver, mainly as the ester, after $24 \mathrm{~h}$.

4. Rats converted carotene injected in an emulsified form into vitamin A. The conversion was effected in a similar manner, but not as efficiently, as when the carotene was injected as aqueous dispersions in earlier experiments (McGillivray \& Worker, 1957).

5. No carotene appeared in the milk and the vitamin $A$ level was unchanged after the intravenous administration of carotene emulsions to lactating goats.

We are grateful to the Department of Scientific and Industrial Research for a grant towards this investigation. One of us (S. Y. T.) is indebted to the Royal Society, the Nuffield Foundation and the Board of the Dairy Research Institute (N.Z.) for a travelling fellowship during the tenure of which the work reported here was carried out. The investigation also forms a section of a thesis submitted by one of us (N.A.W.) in partial fulfilment of the requirements for the degree of Ph.D. of the University of New Zealand. We also wish to thank Miss Fay Frecklington for help with much of the experimental work.

\section{REFERENCES}

Bieri, J. G. (1955). Arch. Biochem. Biophys. 56, 90.

Bieri, J. G. \& Pollard, C. J. (I954). Brit. F. Nutr. 8, 32.

Cartland, G. F. \& Koch, F. C. (1928). Amer. F. Physiol. 85, 540.

Church, D. C., MacVicar, R., Bieri, J. G., Baker, F. H. \& Pope, L. S. (1954). F. Anim. Sci. 13, 677.

Glascock, R. F. (1954). Dairy Sci. Abstr. 16, 858.

Greenberg, R., Levenson, M. \& Rose, H. (1955). Fed. Proc. 14, 63.

Kon, S. K., McGillivray, W. A. \& Thompson, S. Y. (1955). Brit. F. Nutr. 9, 244.

McGillivray, W. A., Thompson, S. Y. \& Worker, N. A. (1956). Brit. F. Nutr. 10, I 26.

McGillivray, W. A. \& Worker, N. A. (1957). Brit. F. Nutr. Ir, 47.

Shafiroff, B. G. P., Mulholland, J. H., Roth, E. \& Baron, H. C. (1949). Proc. Soc. exp. Biol., N.Y., 70, 343 .

Thompson, S. Y., Ganguly, J. \& Kon, S. K. (1949). Brit. Y. Nutr. 3, 50.

Note added in proof. An experiment in which $100 \mu \mathrm{g}$ vitamin A alcohol emulsion were injected into rats gave a total recovery in liver and plasma at $24 \mathrm{~h}$ of $27 \%$, about one-half the corresponding recovery with vitamin A palmitate. 